\title{
NOTES
}

\section{Stalked Sporangia of Polyangium rugiseptum}

\author{
HSIAO-LIN HU, ${ }^{1}$ JOHN E. PETERSON,${ }^{2}$ AND ELLIS R. BROCKMAN ${ }^{1 *}$ \\ Biology Department, Central Michigan University, Mt. Pleasant, Michigan 48859, ${ }^{1}$ and Liberal Arts and Sciences, \\ Kansas State University, Emporia, Kansas $66810^{2}$
}

\begin{abstract}
Although most fruiting bodies (sporangia) of Polyangium rugiseptum are sessile and correspond accurately to the original species description, a microscopic examination of more than 1,000 sporangia revealed the presence of stalked forms in $2.3 \%$ of the specimens.
\end{abstract}

Peterson (2) described a fruiting myxobacterium found on the bark of living trees as "Haploangium rugiseptum." The major distinguishing characteristics which he noted for this species were that its fruiting bodies or sporangia were solitary and sessile. This species was later assigned to the genus Polyangium (1). A main criterion used to distinguish the genus Polyangium from the genus Chondromyces (both genera belong to the family Polyangiaceae) is that the sporangia of Polyangium species are sessile, whereas those of Chondromyces species are stalked.

Reflected light stereomicroscopy (magnifications, $\times 50$ to $\times 200$ ) was used to examine 1,040 fruiting bodies of Polyangium rugiseptum. The specimens used were obtained by one of us (J.E.P.) from trees in Missouri (Quercus nigra,
Juglans nigra, and unidentified species) and are now maintained in the myxobacterial herbarium collection at Central Michigan University. A total of $24(2.3 \%)$ of the sporangia examined were stalked and did not correspond to the species description.

Small pieces of bark bearing air-dried, unfixed fruiting bodies were mounted on stubs with copper conducting tape and Tube Kote (G. C. Electronics, Inc., Rockford, Ill.). The specimens were coated with gold to a thickness of 15 to 20 $\mathrm{nm}$ in a sputter-coating device and observed with a model AMR 1200 scanning electron microscope (Advanced Metals Research, Bedford, Mass.) operated at an accelerating voltage of $25 \mathrm{kV}$. The fruiting bodies were viewed and photographed at a $45^{\circ}$ tilt angle.

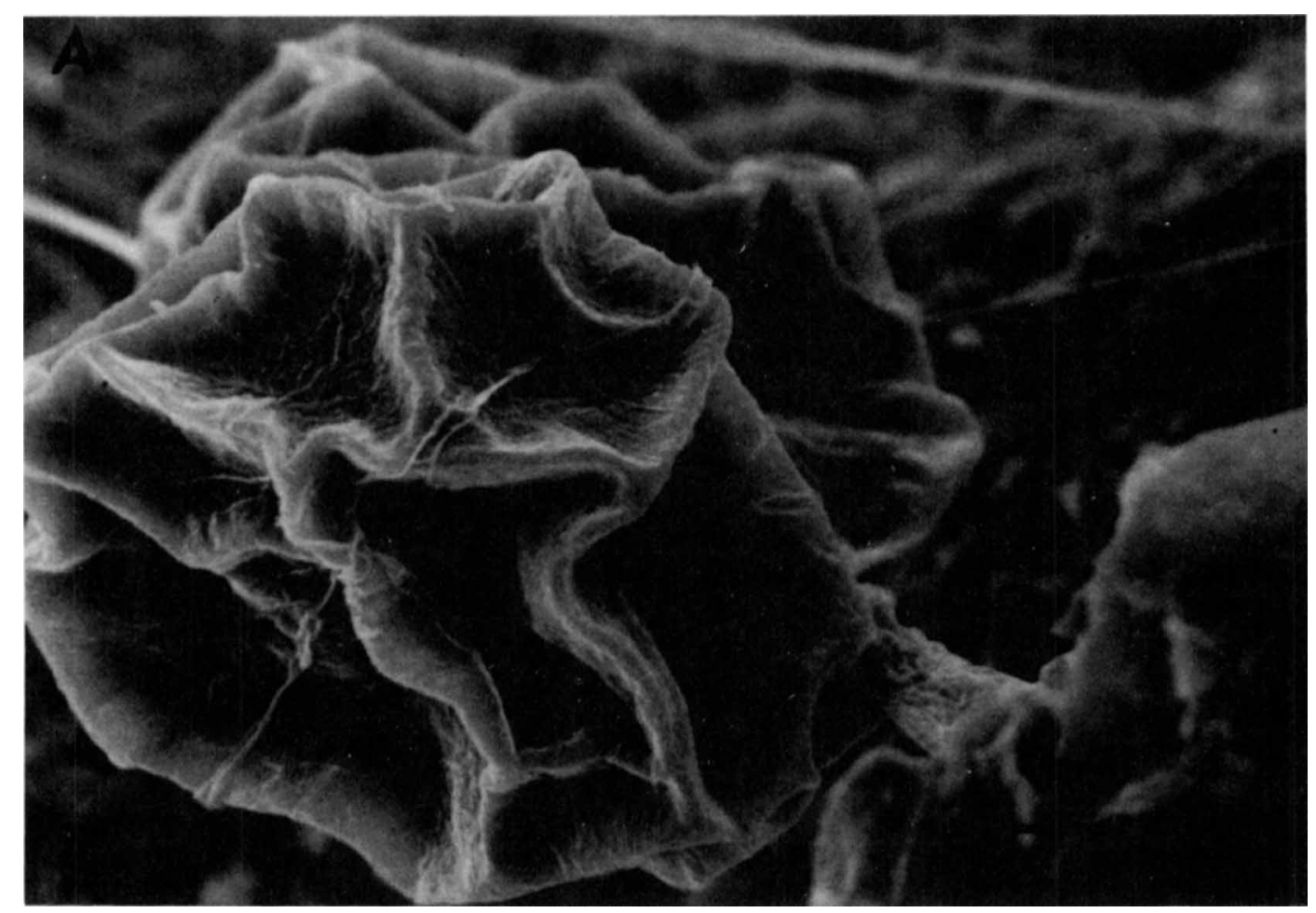

* Corresponding author. 

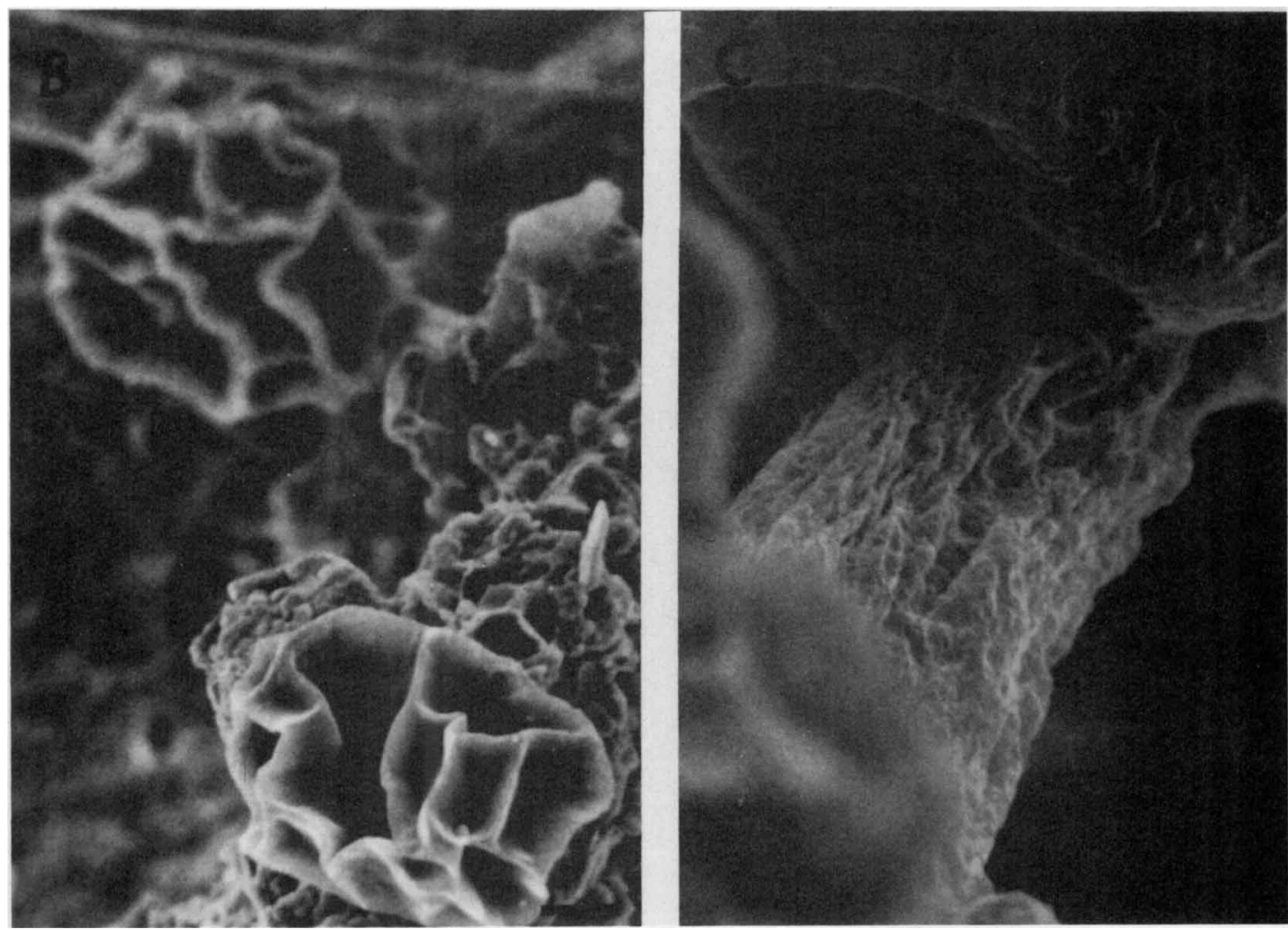

FIG. 1. P. rugiseptum sporangium morphology. (A) Stalked, mature sporangium. Bar $=30 \mu \mathrm{m}$. (B) Stalked (upper) and sessile (lower) sporangia. Bar $=10 \mu \mathrm{m}$. (C) Stalk of the sporangium shown in (A). Bar $=5 \mu \mathrm{m}$.

As shown in Fig. 1, the dry sporangia of $P$. rugiseptum were globose to oval, definitely walled, heavily wrinkled, and measured 75 to 110 by 110 to $140 \mu \mathrm{m}$. They were solitary and predominantly sessile; however, stalked forms were observed (Fig. 1A and the upper sporangium in Fig. 1B). The stalks appeared to have a rough, wrinkled surface texture which was probably an artifact caused by the drying of the fruiting body. The stalk (Fig. 1C) was $13 \mu \mathrm{m}$ in diameter and approximately $20 \mu \mathrm{m}$ long.

Future descriptions of $P$. rugiseptum should reflect that although most of the sporangia are sessile, stalked forms may also occur. It must be emphasized that the stalk may not be readily discernable by low-magnification stereomicroscopy. However, this structure is easily observed by scanning electron microscopy, provided that a tilt angle is used that enables the observer to vicw the lower portion of the heavily wrinkled sporangium.

The occurrence of stalked sporangia at a low frequency may not constitute a major characteristic for this species that would warrant its removal from the genus Polyangium. However, the presence of the stalk should be noted as a minor trait, at least, within the description of the species, and the description of the genus Polyangium should also encompass this characteristic.

\section{LITERATURE CITED}

1. Buchanan, R. E., and N. E. Gibbons (ed.). 1974. Bergey's manual of determinative bacteriology, 8th ed. The Williams \& Wilkins Co., Baltimore.

2. Peterson, J. E. 1959. A monocystic genus of the Myxobacterales (Schizomycetes). Mycologia 51:1-8 